\title{
EDITORIAL
}

\section{Educación artística para fomentar la investigación en cine y audiovisuales}

\author{
Art education to promote film and audiovisual research
}

Ricard HUERTA. Universitat de València (España). ricard.huerta@uv.es

Ricardo DOMíNGUEZ. Universitat de València (España).ricardo.dominguez@uv.es

Resumen: Las tendencias actuales en Educación Artística incorporan de manera decisiva el manejo de la imagen. Fotografía, video, cine, videojuegos, TIC, $\mathrm{y}$ audiovisuales en general, forman parte de un entramado amplio y diverso de posibilidades de creación y difusión de las imágenes. El profesorado de educación en artes está utilizando las imágenes de diferentes formas, y lo que necesitamos es impulsar la investigación sobre estos nuevos usos de la imagen en el ámbito educativo de las artes. Cuando hablamos de imagen no nos referimos únicamente a los usos de las TIC por parte del alumnado y el profesorado, sino que estamos hablando de la posibilidad de investigar desde la propia imagen, con las imágenes, como demuestras las tendencias de las A/R/Tography (Irwin y O’Donoghue, 2012), de la ABR Arts Based Research (Rose, 2016) y de ABER Arts Based Educational Research (Rolling, 2017). Así las cosas, debemos prestar atención a todos los nuevos modelos de investigación en los cuales la imagen forma parte de las posibilidades de indagación y justificación científica en materia de arte y educación(Hernández, 2013).

Palabras clave: educación artística, investigación, arte, formación de profesorado, educomunicación.

Abstract: Current trends in Arts Education decisively incorporate the management
of the image. Photography, video, film, video games, ICT, and audiovisual in
general, are part of a wide and diverse network of possibilities for the creation and
dissemination of images. Teachers of arts education are using images in different
ways, and what we need is to promote research on these new uses of the image in
the educational field of the arts. When we talk about image we do not only refer to
the uses of ICT by students and teachers, but we are talking about the possibility 
of investigating from the own image, with the images, as you demonstrate the tendencies of the A / R / Tography (Irwin and O'Donoghue, 2012), ABR Arts Based Research (Rose, 2016) and ABER Arts Based Educational Research (Rolling, 2017). Thus, we must pay attention to all new research models in which the image is part of the possibilities of inquiry and scientific justification in the field of art and education (Hernández, 2013).

Keywords: art education, research, art, teachers training, educommunication.

\section{Investigar para educar en audiovisuales}

Con el fin de incentivar la investigación sobre educación en cine y audiovisuales, este año 2018 se organizan las IX Jornadas Internacionales de Investigación en Educación Artística. Bajo el título "Cinema i art als entorns educatius" ("Cine y arte en los entornos educativos") estas jornadas se han planteado como un encuentro académico en el cual se abordan los diferentes aspectos que preocupan tanto al sector educativo como al audiovisual. Las jornadas permiten contrastar ideas entre especialistas, de manera que las ponencias surgen como auténticas conversaciones entre educadores, investigadores y cineastas. Entre los invitados e invitadas como ponentes destacamos la presencia de Gabriela Augustowsky (Universidad Nacional de las Artes, Argentina) quien hablará sobre El cine en la infancia y el audiovisual en la escuela; Ricard Huerta (Universitat de València) cuya ponencia versa sobre Cine, educación y diversidad en Latinoamérica; Beatriz González (Ministerio de las Culturas de Chile) quien trata el tema Pensamiento en la imagen: dos lentes sobre un país llamado Chile; Joao Paulo Queiroz (Universidad de Lisboa) cuya intervención es Imágenes desamparadas: pensando las nuevas mediaciones en Portugal; Sidiney Peterson Ferreira de Lima (UNESP, Brasil) que habla sobre Cine y Arte/Educación contemporánea en Brasil; Ricardo Domínguez Ruiz (Universitat de València) que trata el tema Formar y educar en TIC desde las imágenes; María Dolores Arcoba cuyo relato es sobre El autorretrato audiovisual en educación secundaria; Carlos Escaño (Universidad de Sevilla) quien propone Cambios sociales y educación en audiovisuales; Amparo Alonso-Sanz (Universitat de València) con la presentación Entornos propicios para educar en imágenes; Germán Navarro Espinach (Universidad de Zaragoza) que habla de La Edad Media a través del cine: la Trilogía de la Vida de Pasolini; Paula Jardón (Universitat de València) quien sugiere Preparar a docentes con cine y desde el cine; María Dolores Álvarez (Universidad de Granada) que habla sobre Programas educativos e innovación en audiovisuales; Carmen Mayugo (Teleduca) exponiendo el tema Gènero y diversidad en la creación audiovisual participativa; Núria Rajadell (Universitat de Barcelona) con la ponencia El Seminario de Cine Formativo de la Universitat de Barcelona; Ricardo Marín Viadel (Universidad de Granada) que aborda el tema Video, narrativas audiovisuales e Investigación Basada en las Artes; Margaux Lacoste (Relais Culture Europe) que presenta La formación de jóvenes directores de cine en Francia; Roberto Marcelo Falcón (Université París Descartes) con la ponencia Circulación imaginal 
y comprensiva; y Apolline Torregrosa Laboire (Université de Genève) quien habla sobre Cinema directo, aproximaciones pedagógicas de lo cotidiano. El Grupo CREARI de Investigación en Pedagogías Culturales (GIUV2013-103) y el Instituto de Creatividad e Innovaciones Educativas de la Universitat de València, promueven estas Jornadas que consolidan los trabajos realizados por nuestra universidad en los últimos años en relación con la investigación en Educación Artística. Aunamos así los conceptos de investigación y educación en el ámbito del cine y el audiovisual, con el fin de revisar lo que se ha hecho hasta ahora en esta materia, y sobre todo gestionar propuestas de futuro que puedan mejorar la situación (García-Raffi y Jardón, 2018). Las IX Jornadas Internacionales de Investigación en Educación Artística "Cine y arte en entornos educativos" están planteadas desde la perspectiva del Horizonte 2020 (H2020), el Programa Marco de la Comisión Europea para la investigación y la innovación, ya que se trata de una actividad basada en el interés por la innovación. Al reunir a representantes de la sociedad civil, el mundo de los negocios y el mundo académico, ofrecemos excelencia científica, promoviendo la investigación de alto nivel. Obtenemos la participación de diferentes estamentos a través de estrategias que permiten un enfoque diverso, rompiendo obstáculos a la creación audiovisual, fomentando así la investigación y la innovación educativa. La clave está en la investigación, y por tanto, urge contemplar la investigación en cine y audiovisuales como una modalidad más de la investigación en educación artística.

En el número 10 de nuestra revista EARI dedicaremos un monográfico a esta temática tan acuciante e innovadora, como lo es el fomento de la educación artística a través del cine y los audiovisuales. Desde ya os animamos a participar con vuestros artículos en este futuro recopilatorio de EARI que pretende impulsar la difusión de la investigación en educación artística desde la perspectiva del cine y el audiovisual.

\section{Second Round sigue luchando por reivindicar las artes en Educación Secundaria}

En esta misma línea de actuaciones de urgencia para reclamar una mayor presencia de las artes en la educación, el proyecto de innovación educativa "Second Round: Arte y Lucha en Secundaria" tiene previsto realizar su quinta iniciativa anual apostando por el fomento del cine y los audiovisuales. El que hemos denominado en esta ocasión "Second Round: Arte y Lucha en Cine y Audiovisuales" se convierte así en un nuevo escenario para integrar los esfuerzos de profesorado, alumnado y equipos directivos de centros valencianos en los que se van a desarrollar las acciones reivindicativas que promueve "Second Round". Queremos animar al profesorado de artes visuales a investigar sobre todo lo que está realizando cada docente con su alumnado. Es importante destacar la labor de creación de videos por parte del alumnado de secundaria. Muchos de estos trabajos están defendiendo su calidad en certámenes y festivales de cine educativo que proliferan por todo el mundo. En este sentido las distancias ya no existen, ya que las redes permiten compartir información con el resto de países del mundo. Los productos audiovisuales realizados por 
profesorado y alumnado de los centros educativos, en ocasiones asesorados por profesionales del audiovisual, llegan a tener altas cotas de calidad. Además son atrevidos y frescos, ya que no tienen la presión del mercado ni están sometidos a las leyes y convenciones del marketing comercial. Estos productos culturales son al mismo tiempo elementos educativos de primer nivel, composiciones con imágenes y música que pueden llegar a conectar con otras sensibilidades del planeta. Es la magia del audiovisual, y el poder de las imágenes que pueden ser difundidas. Por otra parte, queremos destacar en lo referido al proyecto Second Round que recientemente se ha defendido una tesis doctoral que analiza el papel de este tipo de proyectos que defienden la educación artística en secundaria desde la comunicación y el encuentro en redes. La tesis ha sido presentada por María José Gómez Aguilella, y trata aspectos como la comunicación y las reivindicaciones de Second Round a partir de la problemática de la disminución de la presencia de las artes en secundaria (Gómez Aguilella, 2018).

\section{Problemas en Brasil que son problemas globales para quienes educamos en artes}

La Educación Artística está sufriendo un momento de grave crisis en algunos países de Latinoamérica, y un caso dramático de esta crisis general es el que se vive en Brasil. El año pasado, en esta misma publicación EARI, dedicábamos un análisis específico a esta problemática, centrándonos en el caso de Brasil(Huerta, Domínguez y Barbosa, 2017). La delicada situación que vive este enorme país tiene sus causas de las decisiones del gobierno, que está eliminando las enseñanzas artísticas de los programas educativos. Esto resulta exasperante cuando se trata de un enorme potencial como el que tiene Brasil, que tantos avances ha generado en materia de educación artística. Si utilizamos argumentos de orden cuantitativo para demostrar la importancia de la enseñanza de las artes, también debemos tener en cuenta la educación emocional, aunque este aspecto no interesa a los políticos responsables de la educación en un país como Brasil. Hemos podido comprobar el malestar que genera esta desagradable situación entre los profesionales de la educación artística, en el masivo congreso celebrado el pasado mes de julio en la ciudad de Recife. Precisamente en Recife pasó su infancia Ana Mae Barbosa, referencia internacional de la educación en artes. En Recife se llevó a cabo recientemente el Congreso Internacional SESC de Arte/Educación, que tuvo lugar del 23 al 28 de julio de 2018, organizado por el SESC Pernambuco y la Universidad Federal de Pernambuco. Se rindió homenaje a las arte-educadoras Ingrid Dormien Koudela y Rosa Vasconcellos. A Ingrid por los años de dedicación a la investigación sobre la historia del teatro. A Rosa por su contribución para reestructurar las formas de uso del arte como agente de transformación social en Pernambuco. El tema "Utopías Pedagógicas en Artes como Gesto de (Re) Existencia" orientó los diálogos interdisciplinarios y dio continuidad a las discusiones para profundizar sobre el pensamiento y la práctica educativa de maestros, profesores, estudiantes y artistas. Participaron más de 1000 personas inscritas. No perdamos de vista que personajes clave como Paulo Freire 
iniciaron y desarrollaron activamente su andadura reivindicativa en este importante país (Freire, 2015).

La realización bienal del Congreso Internacional SESC de Arte/Educación reafirma y resalta la marcada presencia del SESC entre las Instituciones que más contribuyen a la promoción de la educación artística y cultural de Brasil. En el momento actual, en que nos encontramos con la necesidad urgente de reflexiones sobre educación, ética, identidad cultural y libertad de expresión política y artística, la educación artística se presenta como herramienta indispensable para trabajar los cuestionamientos y respuestas que permean vertientes intelectuales y prácticas pedagógicas que proliferan, en busca de una educación más lúcida, lúdica y de mayor alcance. Los caminos para esta educación que se quiere más inteligente y creativa atraviesan inevitablemente por los senderos de la educación artística y de los saberes, que se cruzan y proliferan en diálogos interdisciplinarios, entre las ideas y los quehaceres de los profesionales que trabajan teniendo por guía la práctica pedagógica. El VI Congreso Internacional SESC de Arte/Educación, además de reafirmar el compromiso del SESC con la educación y la cultura, invierte en las propuestas pedagógicas dirigidas a una educación de calidad y de personas que desarrollen sus trabajos buscando fortalecer, preservar, proponer e instigar nuevos rumbos y miradas sobre la educación contemporánea.

El problema de Brasil es doblemente grave, debido a las dimensiones del país y a su liderazgo en Iberoamérica. El ascenso al poder de grupos ideológicos ultraconservadores y religiosos en los países del entorno latinoamericano combina a la perfección con las actuales políticas neoconservadoras de los Estados Unidos o las extravagancias de regímenes poco conciliadores como quienes ostentan el poder en países como Rusia. Frente a estas situaciones que nos llevan al enfrentamiento y la pérdida de derechos adquiridos (la educación artística es uno de ellos), muchísima gente está lanzando mensajes de superación, animando a las personas y los colectivos a alzar sus voces contra los atropellos. En este sentido, resulta necesario reapropiarse de las artes, para provocar en cada persona la curiosidad y el deseo de decodificarlas, dándoles significado e importancia para engendrar un mundo mejor y más justo, posibilitando asimismo la construcción de identidades culturales libres y conciliadoras. La fuerza que están teniendo los nuevos discursos que desde los feminismos y la diversidad sexual están reactivando el espíritu combativo frente a las amenazas, sería un buen ejemplo de lo que significa utilizar las artes como resorte de mejora social. La innovación pedagógica implica cambios cualitativos en las prácticas pedagógicas y esos cambios comportan siempre posicionamientos críticos frente a las prácticas tradicionales. La innovación pedagógica es oportuna en el momento educativo actual (Ramon, 2017) y debe incorporarse a todos los espacios disponibles (Alonso-Sanz, 2017).

A pesar de que la escuela sigue mostrando como discurso que prepara al alumnado para el futuro, algo permanece incoherente entre la teoría y la práctica, pues la 
escuela sigue alejada de lo nuevo, del propio alumno, ahogada por los cambios globalizantes. Para salir del ostracismo impuesto por la economía de mercado y dejar de ser reproductora de contenidos que no sirven y no serán utilizados por los alumnos en sus procesos de vida, la escuela debe enfrentarse de forma decidida a los retos globales en sus espacios locales. Se necesita una educación plena, que dé cuenta de sus diversas dimensiones, pues sólo así se conocerá cada cual a sí mismo y reconocerá sus propias cualidades, sus limitaciones y sus potencialidades, poniéndolas todas al servicio de la transformación social (Huerta y Alonso-Sanz, 2017a). En el caso de las universidades, las escuelas y las entidades públicas en general, conviene oxigenar la educación, consolidando espacios significativos, promoviendo el intercambio entre la comunidad científica, estudiantes, educadores y agentes culturales, haciendo permanente el diálogo, la información, la actualización y la crítica en torno a las metodologías y prácticas de la enseñanza aprendizaje, entre quienes se preocupan por una educación de calidad para todos (Barbosa y Cunha, 2010). El papel transformador del profesorado resultará esencial, así como los nuevos usos de la educación artística (Irwin, 2013).

\section{Chile apuesta por las artes con su Semana de la Educación Artística}

El Ministerio de las Culturas, las Artes y el Patrimonio, junto con el Ministerio de Educación, ambos del Gobierno de Chile, apuestan por la Semana de la Educación Artística, una iniciativa de UNESCO a la que se unen cada vez más países e instituciones. Esta celebración busca sensibilizar a la comunidad internacional sobre la importancia de la educación artística, promoviendo la diversidad cultural, el diálogo intercultural y la cohesión social. La plataforma de la SEA se mantiene activa todo el año y se configura como un punto de encuentro para todas las personas e instituciones que quieran participar y deseen intercambiar materiales pedagógicos, convocatorias, actividades o noticias en el ámbito de la educación artística $^{1}$. En Chile, es organizada por la UNESCO, el Ministerio de las Culturas, las Artes y el Patrimonio, el Ministerio de Educación, la Universidad de Chile y Balmaceda Arte Joven, y está dirigida a estudiantes de escuelas y liceos de todo el país, etapas de la enseñanza donde el desarrollo de la artes y la creatividad cumplen un papel fundamental para generar sujetos más libres y conscientes de su entorno (Huerta. y Alonso-Sanz, 2017b).

La reforma educativa ofrece la oportunidad de incorporar el arte como vehículo movilizador, tanto para la reflexión como para la práctica pedagógica a través de las acciones comprometidas por el Plan Nacional de Artes en la Educación, que el Ministerio de las Culturas, las Artes y el Patrimonio junto con el Ministerio de Educación han comprometido y comenzado a implementar. El Plan tiene como objetivo principal contribuir a la mejora de la calidad de la educación de los y

1. http://semanaeducacionartistica.cultura.gob.cl 
las estudiantes que asisten a los establecimientos educativos chilenos, a través de acciones concretas, poniendo en valor el arte en la educación. Y es allí, en la cotidianeidad de los aprendizajes, donde se espera que estas acciones pedagógicas sean un aporte, entregando ideas y orientaciones que puedan ser trabajadas desde todas las asignaturas y en los talleres artísticos. Se intenta que docentes y artistas conformen equipos de trabajo con los y las estudiantes en función de una nueva manera de comprender los procesos de enseñanza y aprendizaje.

Se trata de implicar en esta reforma a todas las artes: arquitectura, artesanías, artes circenses, artes visuales, cine y audiovisual, danza, diseño, fotografía, literatura, música, nuevos medios y teatro. El acercamiento al conocimiento arquitectónico potencia la capacidad de observación del entorno y el pensamiento espacial. El reconocimiento de problemas cotidianos y la búsqueda colectiva de propuestas innovadoras que tiendan a resolverlos, promoviendo el desarrollo de una ciudadanía activa y respetuosa, que valora y cuida los espacios públicos, el entorno y el patrimonio. La artesanía es un saber hacer, un conjunto de conocimientos técnicos y materiales que permiten la realización de productos principalmente hechos a mano. Estos pueden ser de carácter utilitario, estético o simbólico, y siempre son representativos de un medio cultural. En esta disciplina se conjugan artesanía tradicional, artesanía indígena y artesanía contemporánea. El trabajo de artesanía permite desarrollar habilidades manuales, y posibilita el conocimiento histórico e identitario de una localidad, facilitando la vinculación de los/as estudiantes con su propio territorio e identidad local. La artesanía permite sensibilizar a niños, niñas y jóvenes sobre temas relacionados con el arte y las culturas, así como lograr una comprensión respecto del patrimonio material e inmaterial.

El contacto con la artesanía puede ayudar a desarrollar la sensibilidad estética, así como habilidades sociales que serán útiles a lo largo de la vida, y destrezas manuales que transmiten las tradiciones. Esta disciplina desarrolla la identidad tanto individual como cultural de los estudiantes y promueve el interés por la biodiversidad, los pueblos originarios y las culturas tradicionales. Al establecer una relación íntima con los recursos naturales del entorno, permite que se vinculen con la naturaleza, conectándose así con su medio ambiente, rizándose con términos como ecología y sostenibilidad. Promueve el desarrollo de un lenguaje propio que permite ampliar las posibilidades de expresión y comunicación. El trabajo manual ejecutado en grupo permite compartir y socializar no sólo el trabajo artesanal, sino las propias experiencias de vida. Por su parte, la práctica circense ha ido incorporando otras disciplinas del arte en su quehacer, como la danza, el teatro, la interpretación musical y la escenografía. Actualmente ha surgido el circo social, que consiste en poner a disposición de la comunidad las técnicas del circo en tanto herramienta pedagógica, artística y social. Y así en todas las manifestaciones artísticas, donde urge incentivar la innovación desde la creación y la puesta en valor de esencias culturales y tecnológicas. 
Danza, cine, diseño, fotografía, y todas las ramas de las artes deben incorporarse al discurso cotidiano de la ciudadanía, propiciando así elementos de cohesión y sociabilidad, incorporando nuevos recursos y alimentando el respeto hacia las diversidades. Un evento como la Semana de la Educación Artística permite concienciar a la sociedad de la urgencia por establecer nuevos criterios de convivencia.

\section{Un avance sobre el futuro Congreso MAKING / InSEA 2019 en Vancouver (Canadá)}

El Congreso Mundial de InSEA 2019 en la University of British Columbia de Vancouver (Canadá) ofrece a los educadores de arte la oportunidad de teorizar y practicar el "hacer" en la educación artística. A través de una amplia gama de sesiones, talleres y experiencias de campo, los participantes podrán volver a imaginar y reflexionar sobre la "creación" en la educación artística. "Hacer", después de todo, tiene que ver con enfoques materiales e inmateriales, movimientos globales de ideas, cambios anticipados y cambios de percepción. Es de naturaleza proposicional y no prescriptiva. Al ser provocativo y/o evocador, "hacer" también atiende a lo que aún no se ha entendido. Este congreso ofrece una buena oportunidad para enfatizar conceptos como emplazamiento, estar fuera de lugar y estar en el lugar. Por otra parte, la UBC está en el territorio ancestral y antiguo de Musqueam First Nations. En la intersección de perspectivas indígenas y multiculturales, Vancouver se convierte en un punto de encuentro para identidades híbridas, ideas experimentales y conciencia basada en el lugar. ¿Qué entendemos por "hacer" en todas las dimensiones de la educación artística en nuestro siglo? MAKING: Lugar, Indigenizar, Identidad, Experimento. Lugar: ¿Cómo puede afectar la conciencia a la educación artística, especialmente en una época en que la migración, la inmigración y el estatus de refugiado cambian nuestro sentido de ubicación? Indigenizar: ¿Cuáles son las posibilidades y las implicaciones para la educación artística en un contexto de aprendizaje inclusivo? Identidad: ¿Cómo podríamos describir identidades híbridas y repensar nuestras prácticas como resultado? Experimentar: ¿Qué relaciones existen entre riesgos artísticos y pedagógicos, fracasos, éxitos y prácticas estabilizadas / desestabilizadas?

Como parte de la celebración del MAKING, la 6th Conference on Arts-Based Research and Artistic Research tendrá lugar los días 7 y 8 de julio de 2019 en la UBC (Canadá). Se trata de un congreso organizado por el Programa de Educación Artística del Departamento de Currículum y Pedagogía de la Universidad British Columbia, en colaboración con el Departamento de Educación Artística de la Universidad de Granada. Esta reunión académica se centrará en las historias intelectuales de la investigación artística con base educativa, prestando especial atención al lugar de la investigación artística basada en las artes, tanto desde su visión académica como analizando las culturas de investigación y los discursos del arte, la cultura y las prácticas artísticas. Se adopta el formato de simposio orientado 
al estudio (Study-Orientated Symposium). Un simposio suele entenderse como una reunión formal en un entorno académico donde los participantes, expertos en sus campos, se reúnen para ofrecer sus perspectivas académicas e informar sobre la investigación del tema, para discutir estas perspectivas y hacer recomendaciones para acciones orientadas al futuro. Habitualmente un simposio trata sobre un tema único. Todas las contribuciones se enmarcan alrededor de ese tema, con la intención de desarrollar o avanzar en la comprensión más profunda de la temática abordada. Dicho formato se ampliará en este caso prestando especial atención a la importancia de estudiar las ideas que ofrezcan los participantes. Se le dedicará un tiempo importante a la discusión, que vendrá provocada por los documentos breves facilitados por quienes participen. Este formato pretende fomentar y apoyar las conversaciones y discusiones académicas sobre prácticas de investigación y orientaciones teóricas de la investigación artística y educativa. La temática The Intellectual Histories of Arts-Based and Artistic Research se distribuye a partir de las siguientes áreas de interés

Las historias intelectuales de la investigación artística y de base educativa.

- El lugar de la investigación artística y educativa dentro de la academia.

- El lugar de la investigación artística y educativa dentro de las artes visuales.

- El lugar del arte en la investigación artística y su aparición en la investigación educativa.

- Las teorías con las que trabajan los investigadores de arte, utilizando nuestras investigaciones.

- Las luchas históricamente situadas para articular el potencial de la investigación del arte.

La Sociedad Internacional para la Educación a través del Arte (InSEA) representa a miles de miembros en más de 80 países, incluidos profesores en escuelas y universidades, museos, galerías, centros culturales y personas que trabajan como voluntarios en el sector cultural. InSEA es líder mundial en asesoramiento, creación de redes y oportunidades de aprendizaje, un espacio para compartir información y para defender el papel de las artes en la educación. InSEA es una filial de la UNESCO. InSEA2019/Making es el segundo congreso mundial canadiense de InSEA desde el primero en Montreal en 1995. Kit Grauer y Rita Irwin han sido presidentes mundiales de InSEA. El último congreso mundial de InSEA celebrado en Corea contó con más de 1000 asistentes. Para más información sobre este evento se puede consultar www.insea2019.org

También en 2019 tendremos la oportunidad de participar en el Congreso Internacional "Humanidades Digitales y Pedagogías Culturales", que se celebrará en Valencia los días 7 y 8 de noviembre del próximo año. Se trata de una iniciativa del Grupo CREARI de investigación en pedagogías culturales (GIUV2013-103) que de este modo intenta de nuevo avanzar en las nuevas miradas hacia y desde la educación artística, activando resortes innovadores y generando sinergias entre espacios de 
integración. Desde nuestra revista os animamos a participar en estos encuentros y a difundir todas aquellas iniciativas que sirvan para conquistar nuevos territorios para la educación en artes.

\section{EARI 9}

En el número 9 de la revista $E A R I$ se presentan un total de trece artículos, además de una entrevista y cinco recensiones de libros. Destacamos la importante presencia de artículos procedentes de Iberoamérica, lo que avala el carácter internacional de esta publicación.

Dado el carácter dinámico y complejo del contexto educativo, la visión plural recogida a través de estos artículos nos permite realizar diversas aproximaciones a la educación artística y nos ofrece diversos marcos teóricos que nos pueden ayudar a entender el objeto de la misma, sus fines y el papel relevante que debe tener en la formación de las personas.

El artículo de Patricia Benito y Alfredo Palacios, Estudio sobre las concepciones de un grupo de docentes de Educación Primaria sobre la creatividad, indaga sobre las creencias en torno a la naturaleza de la creatividad. La investigación rebela la persistencia de una visión estereotipada del hecho creativo, del mismo modo que se destaca el escaso conocimiento entre los futuros docentes de metodologías pedagógicas que puedan implementar su desarrollo en el aula.

De una manera similar en Educación artística, desconsideración social y falta de expectativas. Consecuencias de la reproducción como paradigma no-educativo, de Carmen Vaquero y Luisa María Gómez del Águila, se desvela, a partir de un estudio realizado durante tres cursos académicos con estudiantes de Grado de Maestro/a en Educación Primaria, la persistencia de determinadas concepciones en torno a la Educación Artística que contribuyen a la tradicional deslegitimación social de la misma.

En este sentido también podemos situar el análisis realizado por Martín Caeiro, María Dolores Callejón y Mohamed Samir Assaleh Assaleh. El artículo La Educación Artística en los Grados de Infantil y Primaria. Un análisis desde las especialidades docentes actuales y propuestas a una especialización en artes, cultura visual, audiovisual y diseño, pone de manifiesto la escasa presencia en los diseños curriculares de las universidades de materias relacionadas con las Artes Plásticas, la Cultura Visual y el Alfabetismo Audiovisual, lo que incrementa un tradicional déficit que también se encuentra presente en el resto de etapas educativas.

Por su parte, Mario Grasso en su artículo Educación por el arte y formación docente: repensar el mandato fundacional disciplinador para transformar la escuela, nos 
propone una reflexión a partir de los postulados teóricos de la Educación por el Arte y su necesaria articulación en la formación docente. En su artículo se recogen algunas de las experiencias realizadas por el mismo entre los años 2012 y 2017, reivindicando las aportaciones de la escuela nueva en los años 50 en Argentina.

La articulación de las prácticas artísticas contemporáneas también está presente en varias de las aportaciones publicadas en este número. Así Daniel Montero en La educación artística como configuración de lo contemporáneo en el arte, argumenta la noción de arte contemporáneo como espacio de experimentación en las escuelas de arte. Su reflexión personal nos invita también a pensar en cómo se relacionan los diferentes lugares del mundo del arte y en la presencia del arte contemporáneo desde la escuela y fuera de ella.

Adriana Raggi, Benjamín J. M. Martínez, María del Carmen Rossette y Luisa Gámez-Tolentino, del grupo de investigación ICDAC (Intervenciones Críticas desde el Arte Contemporáneo), parten de los planteamientos de María Acaso (2018), para presentar diferentes estrategias metodológicas de exploración en la educación en las artes. En su artículo Las propuestas sobre educación artística del grupo Intervenciones Críticas desde el Arte Contemporáneo (ICDAC) se destaca la importancia del trabajo colaborativo y de la investigación artística.

Bajo el título "Paisajes del yo": Simbiosis sensible del cuerpo, espacio y luz en el aula de infantil, Jose María Mesías-Lema y Carlota Sánchez Paz, presentan diferentes experiencias llevadas a cabo en un aula del tercer curso de primer ciclo de educación infantil. Basándose en referentes del arte contemporáneo, llevan a cabo diversas acciones artísticas en las que se favorece la exploración y conocimiento del propio cuerpo en relación con la luz y el espacio.

Por su parte, Vicente Monleón en "El malo de la película”. Estudio de las principales figuras malvadas en la colección cinematográfica clásicos de Disney (1937-2016), analiza los estereotipos y valores que se transmiten a partir de la cinematografía de Walt Disney, a través de los cuales se generan identificaciones y discursos que contribuyen a la construcción o pervivencia de determinados modelos.

En el artículo Derivaciones subjetivas en la contemporaneidad (A propósito Pandemonia Panacea), Edilberto Hernández profundiza en la cuestión de las subjetividades contemporáneas a partir del proyecto artístico Pandemonia Panacea, personaje a través del cual se escenifica una queja, una protesta contra los ideales de belleza, publicidad y fama.

Dos artículos nos acercan a las enseñanzas de Artes Plásticas y Diseño. Así, Marta Quílez en el artículo Alumnado femenino en las enseñanzas de artes plásticas y 
diseño en el sistema educativo público español 1940-2015, analiza la presencia de la mujer en estas enseñanzas, y la persistencia de determinados estereotipos evidenciados en la masculinización de algunas especialidades, fundamentalmente aquellas vinculadas a conocimientos científicos y tecnológicos (por ejemplo, diseño del producto y gráfico).

Por su parte, Ester Parra y Mariano Torres en La gamificación como recurso didáctico en la enseñanza del diseño, proponen una aproximación al papel del juego en la enseñanza del diseño y su valoración como elemento motivador y recurso didáctico.

Por último, dos artículos son narrados desde el relato autobiográfico. A través de Artesanía de vida: Comunicación intersubjetiva que fomenta la interculturalidad en la educación artística comunitaria, Verónica Sahagún realiza una serie de obras en las que utiliza textiles tradicionales mexicanos como modo de indagación y reconocimiento de la influencia familiar y social en la formación de su identidad.

Y el relato de Diego Bernaschina Arte en el silencio: Nueva experiencia hacia el rol del docente hipoacúsico bilingüe, nos aproxima a la cuestión de la inclusión sociallaboral en las escuelas formales como docente/tallerista.

Por último, se presenta la entrevista realizada por Ricard Huerta a Carme Mayugo, educomunicadora y pionera del cine educativo, en las que nos narra su experiencia como coordinadora de Teleduca, colectivo independiente e interdisciplinar de profesionales provenientes de diversas especialidades relacionadas con la educación y la comunicación.

\section{Referencias bibliográficas}

Acaso, M. (2018). Pedagogías invisibles: El espacio del aula como discurso. Madrid: Catarata.

Alonso-Sanz, A. (2017). Repensando tres entornos educativos consolidados. Artseduca, 18, 79-99.

Barbosa, A. M. y Cunha, F. P. (2010). Enfoque triangular en la enseñanza de las artes y culturas visuales. Sao Paulo: Cortez.

Freire, P. (2015). Pedagogia da autonomia: saberes necessários à prática educativa. Rio de Janeiro: Paz e Terra.

García-Raffi, J. V. y Jardón, P. -coord.- (2018) Identidades, cine y educación. València: Tirant lo Blanch. 
Gómez Aguilella, M. J. (2018). Comunicar l'art a l'educació secundària. El projecte Second Round. Tesis doctoral. València: Universitat de València.

Hernández, F. (2013). La cultura visual en los procesos de documentación sobre cómo los jóvenes aprenden dentro y fuera de la escuela secundaria, Visualidades, $11,(2), 73-91$.

Huerta, R. y Alonso-Sanz, A. -coord.- (2017a) Entornos informales para educar en artes. València: PUV.

Huerta, R. y Alonso-Sanz, A. -coord.- (2017b) Nous entorns d'aprenentatge per a les arts $i$ la cultura. València: Tirant lo Blanch.

Huerta, R., Alonso-Sanz, A., Ramon, R. -coord.- (2018) Investigar y educar en diseño. València: Tirant lo Blanch.

Huerta, R., Domínguez, R. y Barbosa, A. M. (2017). Investigar para educar en diseño y otras urgencias de la Educación Artística. EARI Educación Artística Revista de Investigación, 8, 10-23. DOI: https://doi.org/10.7203/eari.8.10790

Irwin, R. (2013). Becoming A/r/tography, Studies in Art Education: A Journal of Issues and Research, 54 (3), 198-215.

Irwin, R. y O’Donoghue, D. (2012). Encountering Pedagogy trough Relational Art Practices, International Journal of Art \& Design Education, 31 (3), 221-236.

Rolling, J. H. (2017). Arts-Based Research in Education. En Leavy, P. (ed.) Handbook of Arts-Based Research. New York: Guilford, pp. 493-510.

Ramon, R. (2017). Pedagogías visuales y artísticas en torno al objeto cotidiano. Artseduca, 18, 30-53.

Rose, G. (2016). Visual Methodologies: An Introduction to Researching with Visual Materials. London: Sage Publications. 